\title{
Erratum to: Pro- and anti-inflammatory cytokines in latent autoimmune diabetes in adults, type 1 and type 2 diabetes patients: Action LADA 4
}

\author{
M. N. Pham • M. I. Hawa • C. Pfleger • M. Roden • \\ G. Schernthaner $\cdot$ P. Pozzilli $\cdot$ R. Buzzetti • \\ W. A. Scherbaum • J. Seissler • H. Kolb • S. Hunter • \\ R. D. G. Leslie • N. C. Schloot • \\ Action LADA Study Group
}

Published online: 18 November 2011

(C) Springer-Verlag 2011

\section{Erratum to: Diabetologia \\ DOI 10.1007/s00125-011-2088-6}

Unfortunately, the median values and interquartile ranges for duration of diabetes in Table 1 were incorrect in this paper. The median value (interquartile range) in years should have read 1.0

The online version of the original article can be found at http://dx.doi. org/10.1007/s00125-011-2088-6.

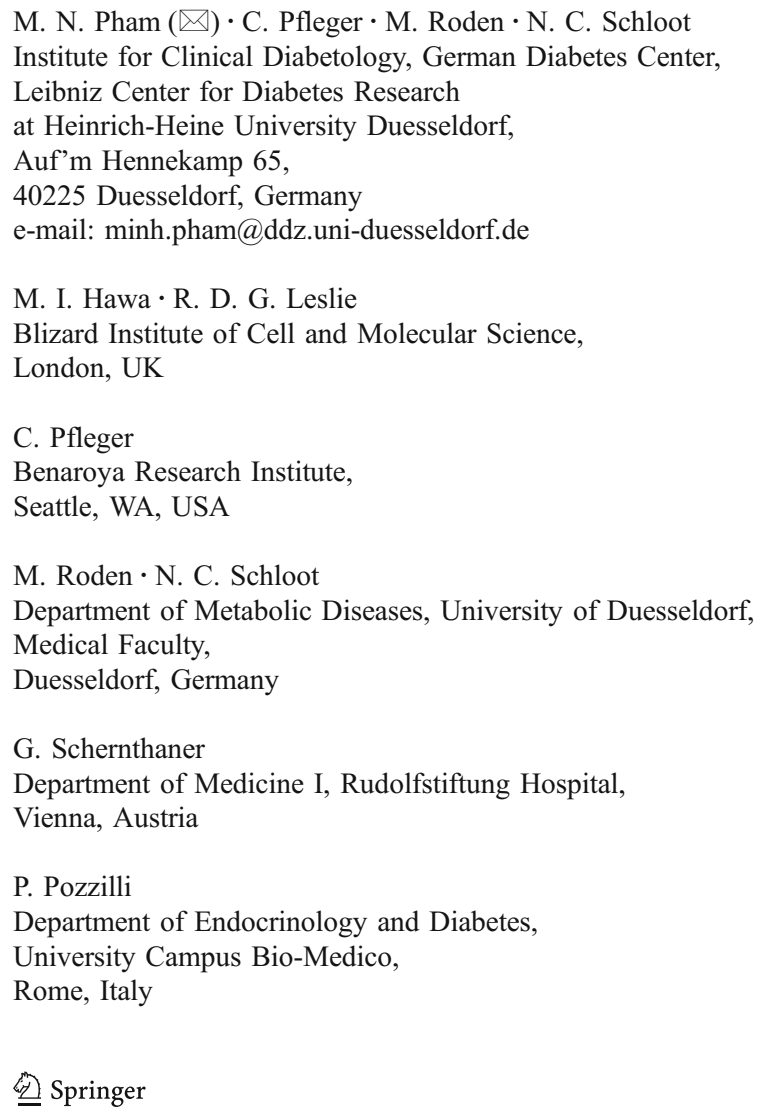

(0.2-1.6) for those with type 1 diabetes, $1.0(0.5-2.3)$ for those with LADA and $1.0(0.3-1.6)$ for those with type 2 diabetes.

The authors regret that the second initial for W. A. Scherbaum was omitted in the author list, and that the affiliation for S. Hunter was incorrect. The details given in this erratum are correct.

\author{
R. Buzzetti \\ Department of Clinical Science, Sapienza University Rome, \\ Rome, Italy
}

\author{
W. A. Scherbaum \\ Department of Endocrinology, Diabetes and Rheumatology, \\ University of Duesseldorf, Medical Faculty, \\ Duesseldorf, Germany \\ J. Seissler \\ Department of Medicine, Ludwig-Maximillians-University, \\ Munich, Germany
}

H. Kolb

Department of Immunobiology Research Group,

University of Duesseldorf, Medical Faculty,

Duesseldorf, Germany
S. Hunter

Regional Centre for Endocrinology and Diabetes, Royal Victoria Hospital,

Belfast, UK 